\title{
The stable fly Stomoxys calcitrans $L$ as a potential vector in the spread of lumpy skin disease virus in Russia: short review
}

\author{
A.V. Sprygin ${ }^{1}$, O.A. Fedorova ${ }^{2}$, A.A. Nesterov $^{1, *}, I . N$. Shumilova $^{1}$, and O.P. Byadovskaya ${ }^{1}$ \\ ${ }^{1}$ Federal State Budgetary Institution "Federal Center for Animal Health Protection", city of Vladimir, \\ the Russian Federation. \\ ${ }^{2}$ All-Russian Research Institute of Veterinary Entomology and Arachnology - branch of the Federal \\ State Budgetary Institution of Science of the Federal Research Center of the Tyumen Scientific \\ Center of the Siberian branch of the Russian Academy of Sciences
}

\begin{abstract}
The paper provides literature review on the relationship among climatic conditions, ecological characteristics of the stable fly (Stomoxys calcitrans L.) and the observed spread of lumpy skin disease across the Russian Federation in 2015-2019. This study was carried out to gain an insight into a role of this potential vector in LSDV transmission. Data analysis shows that the flight activity of the stable fly mainly fits into the seasonal pattern of LSD outbreaks. However, there were outbreaks that occurred outside the period of the stable fly flight activity, pointing to other routes of transmission.
\end{abstract}

\section{Introduction}

The vital activity of representatives of many families of dipterous insects is inextricably linked with agricultural animals, while a number of species cause significant economic damage to livestock. One of these representatives is the autumn stable fly (Stomoxys calcitrans), which is widely distributed in all landscape and geographical zones of the Russian Federation and has an important medical and epidemiological significance as a hematophage and a carrier of human and animal diseases. In this work, we systematize the literature data on the study of the biological characteristics of Stomoxys calcitrans L. and compare it with epizootological data on cattle lumpy skin dermatitis (LSD) in the Russian Federation for the period 2015-2019 in order to determine the role of this carrier in the transmission of the cattle LSD virus in the climatic conditions of the Russian Federation.

\section{Materials and methods}

When writing this article, a compilation of information was made regarding the entomology of the autumn stable fly (Stomoxys calcitrans L.), the spread of lumpy skin dermatitis of cattle in the territory of the Russian Federation in the period 2015-2019, and climatic conditions in

\footnotetext{
*Corresponding author: nesterov@arriah.ru
} 
the regions where the specified disease was recorded. The study used data from domestic and foreign authors, reports on the spread of LSD in cattle of the Federal Service for Veterinary and Phytosanitary Surveillance of the Russian Federation, and meteorological materials from Gismeteo. The analysis of the collected information made it possible to draw a conclusion about the role of the autumn stable fly in the mechanism of transmission and distribution of cattle LSD.

\subsection{General characteristics of Stomoxys calcitrans $L$.}

Autumn stable fliys (Stomoxys calcitrans L.) are small dipterous insects of the Muscidae family, Brachycera Cyclorrapha suborder. Temperature $8-10^{\circ} \mathrm{C}$ is the critical minimum of fly activity, with activity generally starting at $15^{\circ} \mathrm{C}$ or higher. The maximum number in the midland of the Russian Federation is observed in late summer and early autumn, in Central Asia - in July. Despite the fact that this species is thermophilic, its representatives are found in various landscape and climatic zones. Populations are closely related to the habitat of domestic and farm animals, especially cattle; however, they come into contact with animals both indoors and outdoors. Several generations are produced during the warm season. In closed heated rooms, insects can reproduce all year round.

Daily activity of stable fly begins with 8-9 am and ends with the onset of darkness or when the air temperature drops to $10^{\circ} \mathrm{C}$. Maximum activity occurs during the warmest time of the day (from 2-3 pm to 7-8 pm).

The average period of fly development from egg to adult at a temperature of $16^{\circ} \mathrm{C}$ is 20 days, at $25^{\circ} \mathrm{C}-13.5$ days, at $30^{\circ} \mathrm{C}-8$ days, at $36^{\circ} \mathrm{C}-6$ days. Two hours after leaving the puparium, the flies switch to an active lifestyle and no more than 5-7 days later they begin to reproduce.

Both males and females of Stomoxys calcitrans L. are active bloodsuckers. They feed on cattle, less on horses and pigs [1]. With a mass attack of stable flies, body weight gain is reduced by $300 \mathrm{~g}$, milk yield — by $20 \%$ per day, milk fat content — by $0.1 \%$. During one attack on an animal, the insect is usually only partially saturated, which requires repeated attacks on animals, which contributes to infection transmission. Close contact of flies with foci of infections, flights over long distances (up to $29 \mathrm{~km}$ ), confinement of imagos to livestock premises, the ability to retain infectious agents and infestations for a long time all this contributes to the mechanical transfer of many pathogens: anthrax, tularemia, epizootic aphthae, tuberculosis, brucellosis, erysipelas, swine fever, anaplasmosis, su-aura, gabronematosis, setariosis, stenophilariosis and infectious lumpy skin cattle dermatitis $[2,3]$.

Unfortunately, the prevalence and activity of Stomoxys calcitrans L. on the territory of various subjects of the Russian Federation is currently insufficiently systematized.

\subsection{Seasonal activity of Stomoxys calcitrans L.}

The first studies of the fauna and ecology of zoophilic flies in the southern part of the Tyumen region were conducted in 1966. The results showed that the extreme Northern point of detection of the autumn stable fly in Western Siberia is the village of Repalovo in the KhantyMansijsk Autonomous District (60 40 '00" north latitude $69^{\circ} 49^{\prime} 60^{\prime \prime}$ east longitude). At the same time, the beginning of summer is registered from the end of June and lasts approximately 3.5-4 months. The maximum number of insects reaches in the second and third decade of July [4].

On the territory of the Voronezh region, the first St. calcitrans L. individuals are observed in May-June, with the maximum number in late August - early September. 
Studies conducted in the Ivanovo region showed that the beginning of fly flight occurs in the last decade of April, reaching a peak of activity by the end of August. The end of summer is registered in the first decade of October [5].

Long-term (1980-2015) studies of the fauna of the zoophilic fly family in the Samara region revealed only the St. calcitrans $L$ species. Flight is observed from April to October. The peak number of imago is observed in June - August [6].

St. calcitrans $L$. is the most common species of the Baikal-Amur mainline. Depending on the climatic conditions of the location, the departure of autumn stably fly begins from May to June. The maximum number of insects is reached in July - August. The duration of stably fly flight ranges from 90 to 150 [7].

In the Foothills and Mountainous Dagestan, zoophilic flies are active up to 200 days a year, while their maximum number is observed from July to the first decade of October [8].

In the Leningrad and Pskov regions, St. calcitrans L. is a subdominating species. The results of the research indicate that one animal accounts for up to 1000 individuals of the autumn stable flies, which are dispersed indoors.

Analyzing the meteorological data and the dynamics of summer St. calcitrans L., it is possible to identify certain patterns: the increase in the number of flies is closely related to daily average temperature of air and soil; while with decreasing temperature there is a mass occurrence of insects in indoor space [9].

\section{General characteristics of the spread of cattle LSD infection in the Russian Federation in the period from 2015 to 2019}

The first cases of infectious lumpy skin dermatitis in the Russian Federation were registered in July 2015 in animals that grazed freely on mountain pastures of the Tlyaratinsky district (the Republic of Dagestan), on the border with the Republics of Azerbaijan and Georgia. Primary foci were concentrated at relatively small distances from each other along the border, which, taking into account the period of intense insect summer, suggested the spread of the disease by mechanical transfer with insects.

However, the detection of cases at significant distances from the primary foci indicates a significant role of the human factor in the spread of cattle LSD, namely, the transportation of infected animals.

In total, 17 foci of infection were detected in the Republic of Dagestan, the Republic of Chechnya and the Republic of North Ossetia in 2015. At the same time, the vector of the disease spread was directed from the South-West to the North-East. (Figure 1).

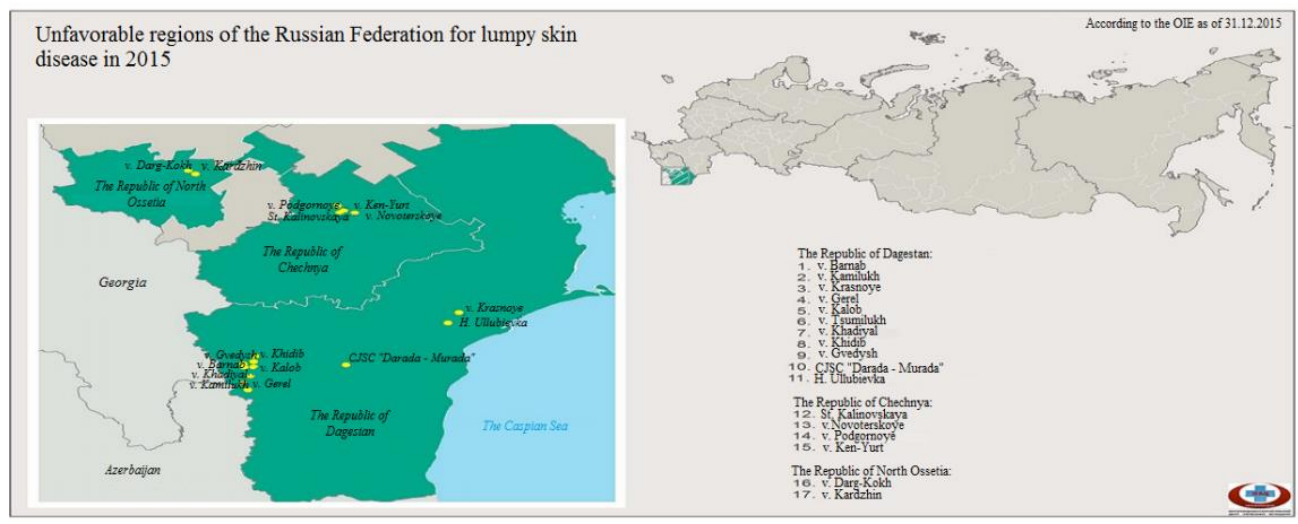

Fig. 1. Map of cattle LSD outbreaks in 2015 in the Russian Federation 
In 2016, 313 foci of cattle LSD were registered on the territory of the Russian Federation. Cases were registered from May (Krasnodar territory and the Republic of Dagestan) to October (North Caucasus and Volga Federal districts). The peak of new outbreaks was observed in July and August.

It is worth noting that some foci of cattle LSD were at a distance of more than $800 \mathrm{~km}$ from the conditional epidemiological center (figure 2). A significant number of outbreaks in the Astrakhan, Volgograd, Rostov regions, Stavropol and Krasnodar territories and the Republic of Kalmykia also fall within the maximum threat zone of $50 \mathrm{~km}$ for insect carriers, which confirms the presence of infection factors other than transfer with insects, such as illegal transportation of sick animals or contaminated vehicles or feed.

Epizootic situation with lumpy dermatitis in the Russian Federation in 2016. $(\mathrm{N}=\mathbf{2 8 9}$ according to data* as of 03.10.2016)

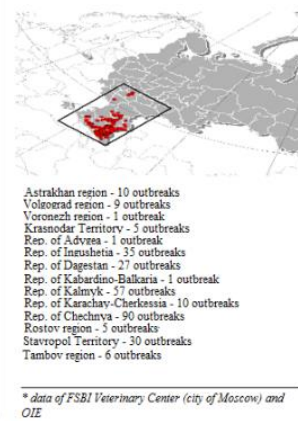

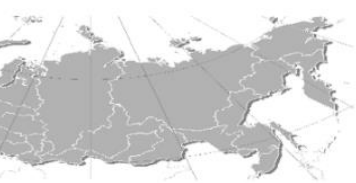

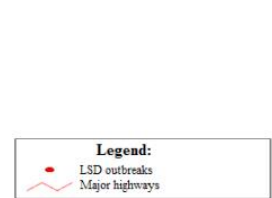

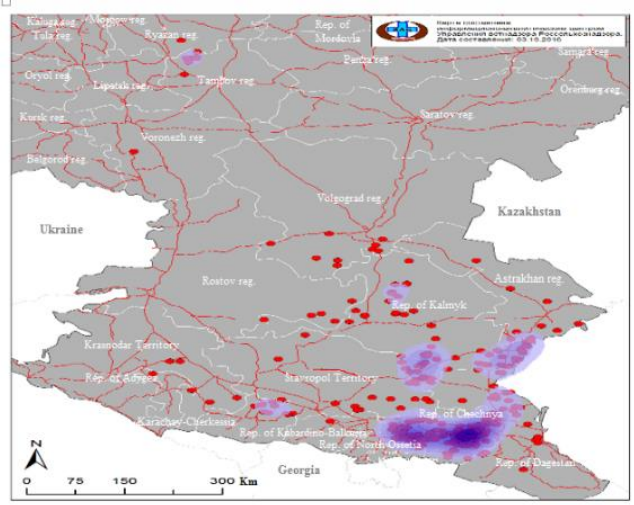

Fig. 2. Map of cattle LSD outbreaks in 2016 in the Russian Federation

It is important to note that all outbreaks in 2015-2016 were caused by a field isolate of the Neethling LSD virus [10].

In 2017, some of the registered foci of infection were caused by vaccine-like isolates of the LSD virus in cattle. All foci were localized on the territory of the North Caucasus and Volga federal districts. The main peak was observed from June to September (42 foci). The exception was 2 foci of cattle LSD registered in the second decade of December. (Fig. 3).

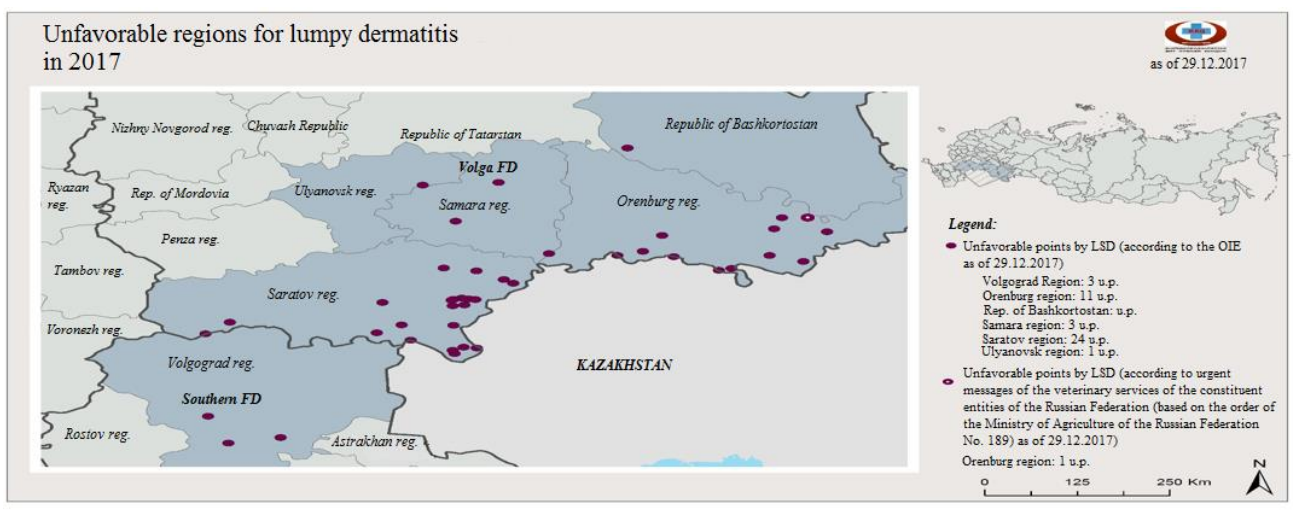

Fig. 3. Map of cattle LSD outbreaks in 2017 in the Russian Federation

Figure 3 shows the area of distribution of cattle LSD in 2017. It can be seen that the outbreaks are located along the border with the Republic of Kazakhstan, which has been using a homologous vaccine against Kenyan cattle LSD since 2016. 
In 2018, 64 foci of infection were registered, between the end of June and the end of November. Foci of infection spread to the Ural (Kurgan and Chelyabinsk regions) and Siberian (Omsk region) federal districts (Fig.4).

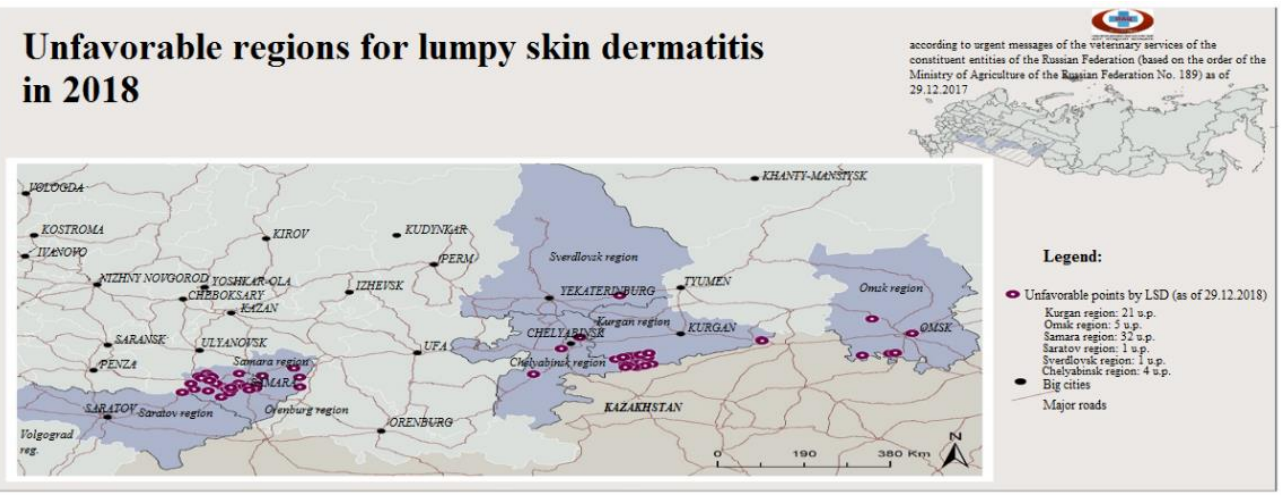

Fig. 4. Map of cattle LSD outbreaks in 2018 in the territory of the Russian Federation

As can be seen from figure 4, most of the foci, as in 2017, were located along the border with the Republic of Kazakhstan. At the same time, all isolated isolates belong to recombinant vaccine-like isolates of the Neethling type [10].

In 2019, 29 foci of the disease were registered. The infection spread in an easterly direction along the state border of the Russian Federation with Kazakhstan, from the Volga region (Saratov region, the Udmurt Republic) to the Ural (Tyumen region) and Siberian (Altai territory, Omsk and Novosibirsk regions) FD. The main peak of the incidence was observed in the warm season (July-October), but in the Udmurt Republic, one focus of cattle LSD was registered in early March, in the conditions of climatic winter (Fig.5).

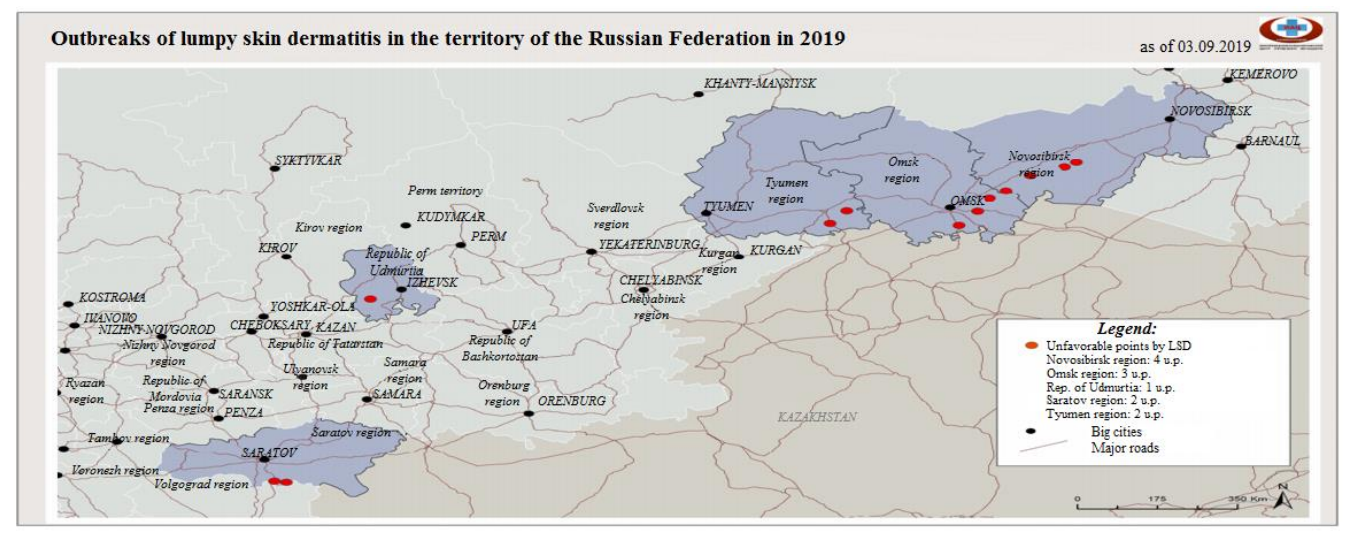

Fig. 5. Map of cattle LSD outbreaks in 2019 in the Russian Federation

\section{Correlation of the period of St. calcitrans L. activity and the frequency of occurrence of cattle LSD foci}

Analyzing the seasonal frequency of cattle LSD outbreaks, it can be noted that the peak incidence of infection occurs in the warm months (depending on the climatic conditions of the location), which indicates a significant role of arthropods in the epizootic process of the disease (Fig.6). However, cases of registration of cattle LSD during the climatic winter cannot be explained solely by entomological factors. 


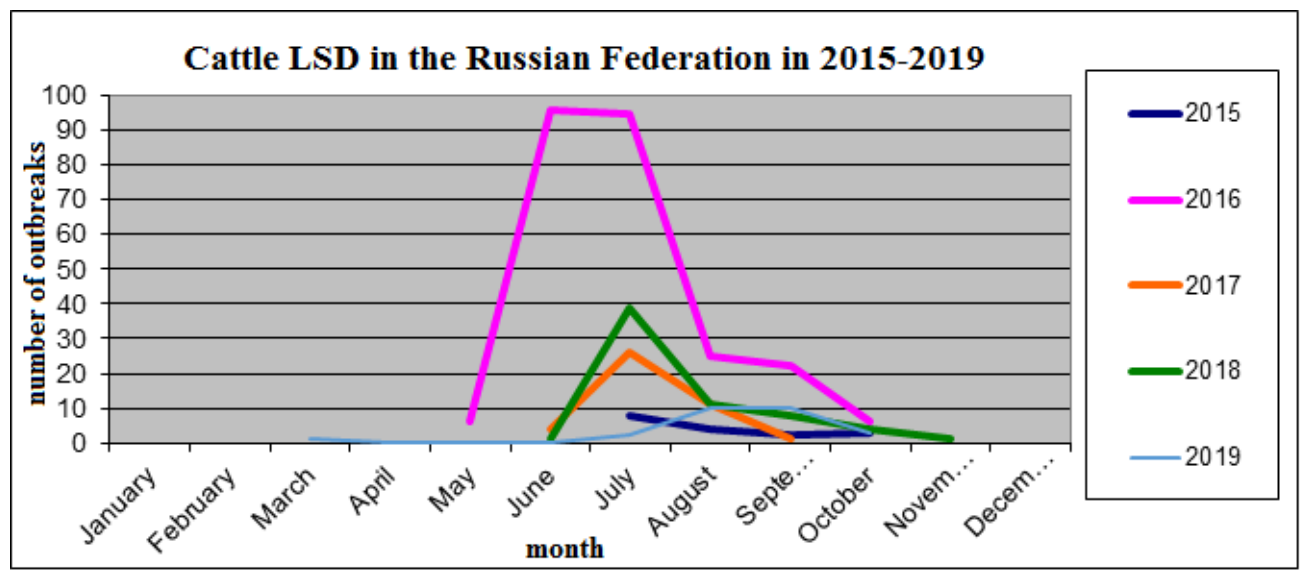

Fig. 6. Seasonality of cattle LSD outbreaks in the period from 2015 to 2019

\section{Conclusions}

Understanding the mechanisms of transmission of the cattle LSD virus is one of the key aspects of strategies for effective control of this disease. It is important to note that the work carried out so far is limited to arthropods living in the Southern hemisphere with a warm climate [11], while representatives of the entomofauna of the Northern hemisphere were not previously studied due to the absence of cattle LSD in Northern latitudes until $2015[3,12]$.

One of the most likely carriers that deserves attention as potential vectors with a wide distribution range is the autumn stable fly Stomoxyscalcitrans [2,13,14]. The hypothesis of transmission involving arthropods is confirmed by the seasonality of the disease with a predominance of cases in the warm months, when the activity of arthropods is maximum [15]. This trend is also observed in the Russian Federation.

The flight of autumn stable fly in the territory of the Russian Federation is celebrated from mid-April to October.

At the same time, it should be noted that some of the outbreaks may have occurred due to the influence of other propagation factors that are not related to the arthropod flight (Fig.2). This is also supported by the appearance of new foci at distances inaccessible to insects [16]. As shown by Baily e.a., (1973) (1973) [17], the migration of the autumn stable fly is $3.2-$ $29 \mathrm{~km}$.

In addition, some of the new foci of the disease occurred in the autumn-winter period, when the intensity of insect flight was minimal or completely absent.

\section{References}

1. A.A. Stackelberg, Synanthropic Diptera of the USSR, 60, 163 (1956)

2. F.M.V. Baldacchino, Transmission of pathogens by Stomoxys flies (Diptera, Muscidae): a review, Parasite, 20(26) (2013)

3. A.P.Y. Sprygin, Transmission of lumpy skin disease: a short review. Virus research, 269:197637 (2019)

4. G.A. Veselkinym, Tr. Questions of Vet. arachno-entomology and vet. Sanitations, 4, 3$10(1972)$

5. M.S. Burtseva, Fauna, ecology, biology of zoophilous flies of the Ivanovo region and measures to combat them, Dis... c.v.sc., 03.00.19 (Parasitology, Ivanovo, 2003) 
6. I.V. Lubvina, Samara Bulletin, 1(14), 38-41 (2016)

7. G.A. Veselkinym, Entomological review, 45(4), 779-793 (1966)

8. F.K. Ragimkhanova, Sh.K. Aliev, Russian parasitological journal, 3, 77-81 (2009)

9. L.A. Grigorievoy, Ecological features of zoophilous flies of cattle in the North-West of the non-Chernozem zone of Russia, Abstract dis. K. b. n., (SP., 1993)

10. A. Sprygin, PLOS ONE, 15(5), e0232584 (2020)

11. E.S.M. Tuppurainen, Transbound. Emerg. Dis., 58, 93-104 (2011)

12. A.E. Sprygin, Transbound. Emerg. Dis., 65(6), 1514-1521 (2018)

13. C.M. Chihota, Attempted mechanical transmission of lumpy skin disease virus by biting insects, Med. Vet. Entomol., 17, 294-300 (2003)

14. C.H.A. Sohier, Sci Rep. of, (9), 20076 (2019)

15. P.S.B. Mafirakureva,Tropical Animal Health and Production., 49(1), 47-54 (2017)

16. A.M.V. Karaulov, Forecast for nodular dermatitis in cattle in the Russian Federation for 2017, 135-163 (2016)

17. D.C. Baily, T.L. Whitfield, B.J. Smi111e, J. Econ. Entomol, 66(2), 410-411 (1973) 